Pacific Journal of Mathematics

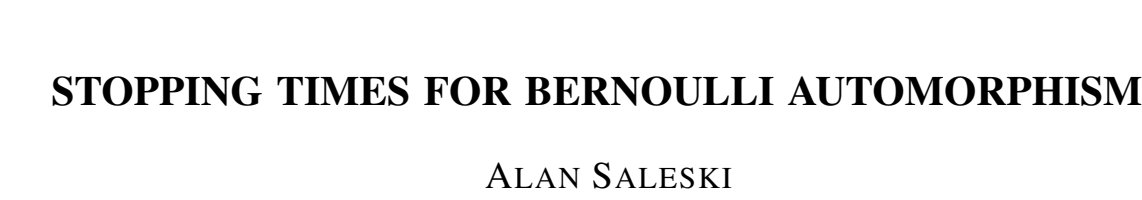




\section{STOPPING TIMES FOR BERNOULLI AUTOMORPHISMS}

\section{Alan Saleski}

The purpose of this note is to study a certain class of stopping times for Bernoulli automorphisms by means of the Friedman-Ornstein results concerning weakly Bernoulli partitions.

1. Introduction. Let $T$ be an automorphism of the non-atomic Lebesgue space $(X, \mathfrak{N}, \mu)$ and let $\theta: X \rightarrow Z^{+}$be a measurable function. If the transformation $S=T^{\theta}$ defined by $S(x)=T^{\theta(x)}(x)$, for $x \in X$, is an automorphism of $X$ then $\theta$ is called a stopping time for $T$. Such a stopping time will be said to be of $n$th order (where $n$ is a positive integer or $\infty$ ) if there exists a decreasing sequence $D_{1} \supset D_{2} \supset D_{3} \supset \ldots$ of measurable subsets of $X$ satisfying

(a) $\mu\left(D_{n}\right)>0$ and $\mu\left(D_{n+1}\right)=0$ if $n$ is finite

or

(b) $\mu\left(D_{i}\right)>0$ for all $i$ and $\mu\left(\cap_{1}^{\infty} D_{i}\right)=0$ if $n$ is infinite such that $T^{\theta}$ coincides (modulo 0 ) with the automorphism $M$ defined by

$$
M(x)=T_{D_{0}} \circ T_{D_{1}} \circ T_{D_{2}} \circ \ldots \circ T_{D_{s-1}} \circ T_{D_{s}}(x), \quad \text { for } x \in D_{s}-D_{s+1},
$$

for $s=0,1,2, \cdots, n-1$, where $D_{0}=X$ and $T_{D_{i}}$ denotes the automorphism induced by $T$ on $D_{i}$.

Neveu has shown [3] that every stopping time $\theta$ for which $T^{\theta}$ is ergodic is an $n$th order stopping time for a unique $n$. Moreover, the sets $D_{1}, D_{2}, \cdots$ are also unique (modulo 0 ). It follows from the work of Belinskaya [1] that if $\theta$ is an $n$th order stopping time for $T$ then $h\left(T^{\theta}\right)=n h(T)$.

The purpose of this note is to study certain ergodic properties of $T^{\theta}$ under the hypothesis that $T$ be a Bernoulli automorphism. For definitions and notation of entropy theory the reader is referred to [4] and [6]. For convenience of notation we shall let $P_{n}^{m}=$ $\bigvee_{n}^{m} T^{i} P, P^{+}=\bigvee_{0}^{\infty} T^{i} P$, and $P^{-}=\bigvee_{-\infty}^{0} T^{i} P$ where $m>n$ and $P$ is a partition of $X$.

2. We now establish a result, using a technique developed in [7], concerning a special class of stopping times for a Bernoulli automorphism.

Let $T$ be a Bernoulli automorphism of $X$, and let $B$ be a Bernoulli partition for $T$, i.e., $B$ is a generator and the orbit of $B$ under $T$, $\left\{T^{i} B: i \in Z\right\}$, is a jointly independent sequence of partitions. We let $\mathscr{F}_{B}$ denote the collection of all measurable partitions $P$ of $X$ for which $H\left(P^{+} \mid B^{+}\right)+H\left(P^{-} \mid B^{-}\right)<\infty$. 
THEOREM. Let $T$ be a Bernoulli automorphism of $X$ and $B$ be a Bernoulli partition. Let $\theta$ be an nth order stopping time for $T$ and let $D_{1}, D_{2}, \cdots$ be the sets corresponding to $\theta$. Let $P$ denote the partition $\left\{X-D_{1}, D_{i}-D_{i+1}: i=1,2, \cdots\right\}$. Suppose $P \in \mathscr{F}_{B}$. Then $S=T^{\theta}$ is weakly mixing if and only if $S$ is a Bernoulli automorphism having entropy $n h(T)$.

To prove this theorem we will require the following lemma.

Lemma 1. Let $A, F$ and $C$ be measurable partitions of $X$ such that $F$ is independent of $A$ and $H(C \mid A)<\varepsilon$. Let $D \leqq C$ be finite. Then

$$
H(D \mid F) \geqq H(D)-\varepsilon .
$$

Proof. Choose $F_{n} \leqq F$ such that $F_{n} \uparrow F$ and $H\left(F_{n}\right)<\infty$. Then

$$
H\left(F_{n} \mid D\right) \geqq H\left(F_{n} \mid A\right)-H(D \mid A) \geqq H\left(F_{n}\right)-\varepsilon .
$$

Hence

$$
H\left(D \mid F_{n}\right) \geqq H(D)-\varepsilon .
$$

Letting $n \rightarrow \infty$ we obtain the desired result.

Proof of theorem. Let $K$ be any positive integer, $\varepsilon>0$, and $Q=B_{-K}^{K}$ (this notation will be employed only with respect to the automorphism $T)$. Choose $N>0$ such that $H\left(P_{-\infty}^{0} \mid B_{-\infty}^{N}\right)<\varepsilon / 4$ and $H\left(P_{0}^{\infty} \mid B_{-N}^{\infty}\right)<\varepsilon / 4$. Let $R=\max \{N, K\}$. If $S$ is weakly mixing then there is an integer $M>R$ for which

$$
H\left(S^{-M} Q \mid B_{-R}^{R}\right) \geqq H\left(S^{-M} Q\right)-\frac{\varepsilon}{4} .
$$

Since

$$
S^{-M} Q \leqq B_{-\infty}^{K} \vee P_{-\infty}^{0}
$$

and

$$
H\left(B_{-\infty}^{R} \vee P_{-\infty}^{0} \mid B_{-\infty}^{R}\right)<\frac{\varepsilon}{4},
$$

Lemma 1 implies that

$$
H\left(S^{-M} Q \vee B_{-R}^{R} \mid B_{R+1}^{\infty}\right) \geqq H\left(S^{-M} Q \vee B_{-R}^{R}\right)-\frac{\varepsilon}{4} .
$$

Using the fact that 


$$
\bigvee_{0}^{\infty} S^{j} Q \leqq B_{-K}^{\infty} \vee P_{0}^{\infty}
$$

we obtain:

$$
\begin{aligned}
H\left(S^{-M} Q||_{0}^{\infty} S^{j} Q\right) & \geqq H\left(S^{-M} Q \mid B_{-R}^{\infty} \vee P_{0}^{\infty}\right) \\
& \geqq H\left(S^{-M} Q \mid B_{-R}^{\infty}\right)-H\left(P_{0}^{\infty} \mid B_{-R}^{\infty}\right) \\
& \geqq H\left(S^{-M} Q \mid B_{-R}^{\infty}\right)-\frac{\varepsilon}{4} \\
& =H\left(S^{-M} Q \vee B_{-R}^{R} \mid B_{R+1}^{\infty}\right)-H\left(B_{-R}^{R} \mid B_{R+1}^{\infty}\right)-\frac{\varepsilon}{4} \\
& \geqq H\left(S^{-M} Q \vee B_{-R}^{R}\right)-H\left(B_{-R}^{R}\right)-\frac{\varepsilon}{2} \\
& =H\left(S^{-M} Q \mid B_{-R}^{R}\right)-\frac{\varepsilon}{2} \\
& \geqq H\left(S^{-M} Q\right)-\varepsilon .
\end{aligned}
$$

Since $K$ and $\varepsilon$ were arbitrary, there exists an integer $p>N$ for which

$$
H\left(S^{-p}\left(B_{-R}^{R}\right) \mid \bigvee_{0}^{\infty} S^{j}\left(B_{-R}^{R}\right)\right) \geqq H\left(B_{-R}^{R}\right)-\frac{\varepsilon}{2}
$$

Now, for all $t>p$,

$$
\begin{aligned}
H\left(\bigvee_{p}^{t} S^{i} Q \mid \bigvee_{-\infty}^{0} S^{j} Q\right) & \geqq H\left(\bigvee_{p}^{t} S^{i} Q \mid B_{-\infty}^{R} \vee P_{-\infty}^{0}\right) \\
& \geqq H\left(\bigvee_{p}^{t} S^{i} Q \mid B_{-\infty}^{R}\right)-H\left(P_{-\infty}^{0} \mid B_{-\infty}^{R}\right) \\
& \geqq H\left(\bigvee_{p}^{t} S^{i} Q \mid B_{-\infty}^{R}\right)-\frac{\varepsilon}{4} \\
& =H\left(\bigvee_{p}^{t} S^{i} Q \mid B_{-R}^{R} \vee B_{-\infty}^{-R-1}\right)-\frac{\varepsilon}{4} \\
& =H\left(\bigvee_{p}^{t} S^{i} Q \vee B_{-R}^{R} \mid B_{-\infty}^{-R-1}\right)-H\left(B_{-R}^{R}\right)-\frac{\varepsilon}{4} \\
& \geqq H\left(\bigvee_{p}^{t} S^{i} Q \vee B_{-R}^{R}\right)-\frac{\varepsilon}{2}-H\left(B_{-R}^{R}\right) \\
& \geqq H\left(\bigvee_{p}^{t} S^{i} Q\right)+H\left(B_{-R}^{R}\right)-\varepsilon-H\left(B_{-R}^{R}\right) \\
& =H\left(\bigvee_{p}^{t} S^{i} Q\right)-\varepsilon .
\end{aligned}
$$

This verifies that $Q$ is a weakly Bernoulli partition for $S$ and thus, applying the Friedman-Ornstein theorem [2], $Q$ generates a Bernoulli 
factor. As a result of Ornstein's theorem 2 of [5], letting $K \rightarrow \infty$, we find that $S$ is actually a Bernoulli automorphism.

3. We now illustrate some consequences of the theorem in the case of second order stopping times.

We omit the proofs of the following two elementary lemmas.

Lemma 2. If $R$ is an automorphism of $X$ and $A$ is a measurable subset of $X$ for which $\bigcup_{0}^{\infty} R^{i} A=X$ then $R$ is ergodic if and only if $R_{A}$ is ergodic.

LEMma 3. Let $R$ be an automorphism of $X$. If $R^{2}$ is weakly mixing then so is $R$.

Proposition 1. Let $T$ be an automorphism of $X$ and let $\theta$ be a second order stopping time for $T$. Then $S=T^{\theta}$ is ergodic if and only if both $T$ and $\left(T_{D_{1}}\right)^{2}$ are ergodic.

Proof. If $S=T^{\theta}$ is ergodic it is well-known that $S_{D_{1}}=\left(T_{D_{1}}\right)^{2}$ is also ergodic. Hence $T_{D_{1}}$ is ergodic. From $\bigcup_{0}^{\infty} S^{i} D_{1}=X$ it follows that $\bigcup_{0}^{\infty} T^{i} D_{1}=X$. Applying Lemma 2 we obtain the ergodicity of $T$.

Conversely suppose $T$ and $\left(T_{D_{1}}\right)^{2}$ are ergodic. In view of Lemma 2 , it suffices to show $\bigcup_{0}^{\infty} S^{i} D_{1}=X$. One easily verifies that

$$
S\left(\bigcup_{0}^{n} T^{i} D_{1}\right) \cup D_{1}=\bigcup_{0}^{n+1} T^{i} D_{1} \quad(\text { for } n \geqq 0)
$$

from which is obtained $\bigcup_{0}^{\infty} S^{i} D_{1}=\bigcup_{0}^{\infty} T^{i} D_{1}=X$.

Corollary 1. Let $T$ be a Bernoulli automorphism of $X, B$ be a Bernoulli partition for $T$, and $\theta$ be a second order stopping time defined by choosing $D_{1}$ to be an atom of $\bigvee_{-K}^{K} T^{i} B$ for any integer $K$. Then $S=T^{\theta}$ is ergodic.

Proof. It follows from a corollary of Theorem 1 of [7] that $T_{D_{1}}$ is Bernoulli and hence, of course, $\left(T_{D_{1}}\right)^{2}$ is ergodic. Thus Proposition 1 yields that $S$ is ergodic.

Proposition 2. Let $T$ be a Bernoulli automorphism of $X$ and $B$ be a Bernoulli partition for $T$. Let $\theta$ be a second order stopping time for which $\left\{D_{1}, X-D_{1}\right\} \in \mathscr{F}_{B}$. Then the following are equivalent:

(a) $T_{D_{1}}$ is weakly mixing.

(b) $T_{D_{1}}$ is Bernoulli.

(c) $S_{D_{1}}$ is Bernoulli.

(d) $S_{D_{1}}$ is weakly mixing. 
Proof. Using Lemma 3 together with the observation that $S_{D_{1}}=$ $\left(T_{D_{1}}\right)^{2}$ and Theorem 1 of [7] the proof is immediate.

Proposition 3. Let $T$ be a Bernoulli automorphism of $X$ and $B=\left\{B^{1}, B^{2}, \cdots, B^{K}\right\}$ be a Bernoulli partition for $T$. Let $\theta$ be the second order stopping time for $T$ defined by choosing $D_{1}=B^{1}$. Then $S=T^{\theta}$ is mixing.

Proof. Let $K$ be a fixed positive integer and set $Q=B_{-K}^{K}$. As a consequence of the definition of $S$ one can verify that

$$
\bigvee_{K}^{\infty} S^{i} Q \leqq B_{1}^{\infty} \text { and } \bigvee_{-\infty}^{-K} S^{i} Q \leqq B_{-\infty}^{0}
$$

So if $A$ and $B$ are members of the algebra generated by the atoms of $Q$ then $\mu\left(S^{j} A \cap B\right) \rightarrow \mu(A) \mu(B)$. Now a standard approximation argument will show that $S$ is mixing.

CoRollary 2. Under the hypotheses of Proposition 3 the automorphism $S=T^{\theta}$ is Bernoulli.

Proof. This follows immediately from our theorem.

\section{REFERENCES}

1. R. M. Belinskaya, Generalized degrees of automorphism and entropy, Siberian J. Math., 11 No. 4, (1970), 739-749.

2. N. A. Friedman and D. Ornstein, On isomorphism of weak Bernoulli transformations, Advances in Math., 5 (1970), 365-394.

3. J. Neveu, Temps d'arrêt d'un système dynamique, Z. Wahrscheinlichkeitstheorie verw. Geb., 13 (1969), 81-94.

4. D. Ornstein, Bernoulli shifts with the same entropy are isomorphic, Advances in Math., 4 (1970), 337-352.

5. - Two Bernoulli shifts with infinite entropy are isomorphic, Advances in Math., 5 (1971), 339-348.

6. W. Parry, Entropy and Generators in Ergodic Theory, Benjamin, New York, 1969.

7. A. Saleski, On induced transformations of Bernoulli shifts, Math. Systems Theory, 7 No. 1, (1973), 83-96.

Received July 17, 1973.

UNIVERSITY OF VIRGINIA 



\section{PACIFIC JOURNAL OF MATHEMATICS}

EDITORS

RICHARD ARens (Managing Editor)

University of California

Los Angeles, California 90024

\section{R. A. Beaumont}

University of Washington

Seattle. Washington 98105

\section{J. DugundjI}

Department of Mathematics University of Southern California Los Angeles, California 90007

D. Gilbarg and J. Milgram

Stanford University

Stanford. California 94305

\section{ASSOCIATE EDITORS}
E. F. BECKENBACH
B. H. NEUMANN
F. WOLF
K. Yoshida

\section{SUPPORTING INSTITUTIONS}

\author{
UNIVERSITY OF BRITISH COLUMBIA \\ CALIFORNIA INSTITUTE OF TECHNOLOGY \\ UNIVERSITY OF CALIFORNIA \\ MONTANA STATE UNIVERSITY \\ UNIVERSITY OF NEVADA \\ NEW MEXICO STATE UNIVERSITY \\ OREGON STATE UNIVERSITY \\ UNIVERSITY OF OREGON \\ OSAKA UNIVERSITY
}

\author{
UNIVERSITY OF SOUTHERN CALIFORNIA \\ STANFORD UNIVERSITY \\ UNIVERSITY OF TOKYO \\ UNIVERSITY OF UTAH \\ WASHINGTON STATE UNIVERSITY \\ UNIVERSITY OF WASHINGTON

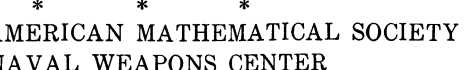

The Supporting Institutions listed above contribute to the cost of publication of this Journal, but they are not owners or publishers and have no responsibility for its content or policies.

Mathematical papers intended for publication in the Pacific Journal of Mathematics should be in typed form or offset-reproduced, (not dittoed), double spaced with large margins. Underline Greek letters in red, German in green, and script in blue. The first paragraph or two must be capable of being used separately as a synopsis of the entire paper. Items of the bibliography should not be cited there unless absolutely necessary, in which case they must be identified by author and Journal, rather than by item number. Manuscripts, in duplicate if possible, may be sent to any one of the four editors. Please classify according to the scheme of Math. Rev. Index to Vol. 39. All other communications to the editors should be addressed to the managing editor, or Elaine Barth, University of California, Los Angeles, California, 90024.

100 reprints are provided free for each article, only if page charges have been substantially paid Additional copies may be obtained at cost in multiples of 50 .

The Pacific of Journal Mathematics is issued monthly as of January 1966. Regular subscription rate: $\$ 72.00$ a year (6 Vols., 12 issues). Special rate: $\$ 36.00$ a year to individual members of supporting institutions.

Subscriptions, orders for back numbers, and changes of address should be sent to Pacific Journal of Mathematics, 103 Highland Boulevard, Berkeley, California, 94708.

\section{PUBLISHED BY PACIFIC JOURNAL OF MATHEMATICS, A NON-PROFIT CORPORATION}

Printed at Kokusai Bunken Insatsusha (International Academic Printing Co., Ltd.), 270, 3-chome Totsuka-cho. Shinjuku-ku, Tokyo 160. Japan.

Copyright (C) 1973 by Pacific Journal of Mathematics Manufactured and first issued in Japan 


\section{Pacific Journal of Mathematics}

\section{Vol. 52, No. $2 \quad$ February, 1974}

Harm Bart, Spectral properties of locally holomorphic vector-valued functions .....

J. Adrian (John) Bondy and Robert Louis Hemminger, Reconstructing infinite

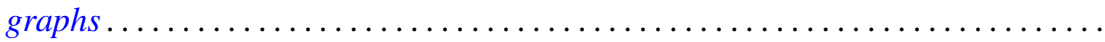

Bryan Edmund Cain and Richard J. Tondra, Biholomorphic approximation of planar

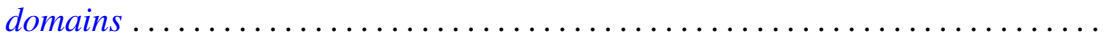

Richard Carey and Joel David Pincus, Eigenvalues of seminormal operators,

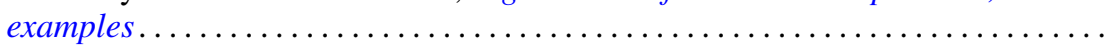

Tyrone Duncan, Absolute continuity for abstract Wiener spaces . . . . . . . . . . . . Joe Wayne Fisher and Louis Halle Rowen, An embedding of semiprime

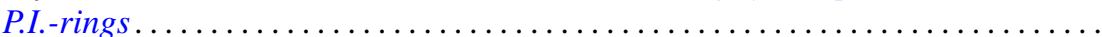

Andrew S. Geue, Precompact and collectively semi-precompact sets of semi-precompact continuous linear operators. . . . . . . . . . . . . . . .

Charles Lemuel Hagopian, Locally homeomorphic $\lambda$ connected plane continua ..... . Darald Joe Hartfiel, A study of convex sets of stochastic matrices induced by

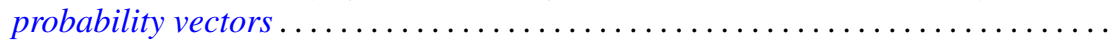

Yasunori Ishibashi, Some remarks on high order derivations $\ldots \ldots \ldots \ldots \ldots \ldots \ldots$ Donald Gordon James, Orthogonal groups of dyadic unimodular quadratic forms.

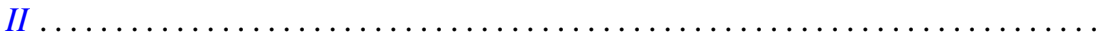

Geoffrey Thomas Jones, Projective pseudo-complemented semilattices . . . . . . . . . Darrell Conley Kent, Kelly Denis McKennon, G. Richardson and M. Schroder,

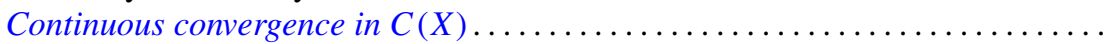

J. J. Koliha, Some convergence theorems in Banach algebras ...

Tsang Hai Kuo, Projections in the spaces of bounded linear oper

George Berry Leeman, Jr., A local estimate for typically real functions . .

475

Andrew Guy Markoe, A characterization of normal analytic spaces by the

homological codimension of the structure sheaf .........

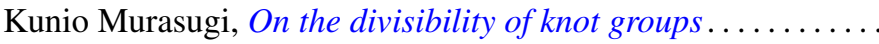

John Phillips, Perturbations of type I von Neumann algebras.

Billy E. Rhoades, Commutants of some quasi-Hausdorff matrices . .

David W. Roeder, Category theory applied to Pontryagin duality

Maxwell Alexander Rosenlicht, The nonminimality of the differential closure .

Peter Michael Rosenthal, On an inversion theorem for the general Mehler-Fock transform pair.

Alan Saleski, Stopping times for Bernoulli automorphisms

John Herman Scheuneman, Fundamental groups of compact complete locally affine complex surfaces. II. ........................

Vashishtha Narayan Singh, Reproducing kernels and operators with a cyclic vector. I. .

Peggy Strait, On the maximum and minimum of partial sums of random variables.

J. L. Brenner, Maximal ideals in the near ring of polynomials modulo 2 .

Ernst Gabor Straus, Remark on the preceding paper: "Ideals in near rings of polynomials over a field" ..........................

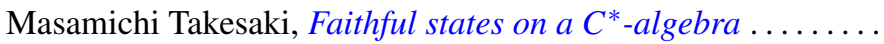

R. Michael Tanner, Some content maximizing properties of the regular simplex.

Andrew Bao-hwa Wang, An analogue of the Paley-Wiener theorem for certain

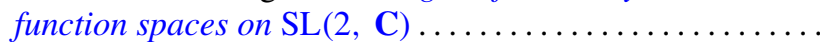

